\title{
Release profiles and morphological characterization by atomic force microscopy and photon correlation spectroscopy of ${ }^{99 \mathrm{~m}}$ Technetium-fluconazole nanocapsules
}

\author{
Danielle Nogueira de Assis ${ }^{a}$, Vanessa Carla Furtado Mosqueira ${ }^{b, *}$, José Mário Carneiro Vilela $^{\mathrm{c}}$, \\ Margareth Spangler Andrade ${ }^{c}$, Valbert Nascimento Cardoso ${ }^{\mathrm{a}}$ \\ ${ }^{a}$ Departamento de Análises Clínicas, Faculdade de Farmácia, Universidade Federal de Minas Gerais, Av. Antônio Carlos, \\ 6627 Belo Horizonte, MG 31270-901, Brazil \\ ${ }^{\mathrm{b}}$ Departamento de Farmácia, Escola de Farmácia, Universidade Federal de Ouro Preto, \\ Rua Costa Sena, 171 Centro, Ouro Preto, MG 35400-000, Brazil \\ ${ }^{\mathrm{c}}$ Fundação Centro Tecnológico de Minas Gerais - CETEC, Avenida José Cândido da Silveira, \\ 2000 Belo Horizonte, MG 31170-000, Brazil
}

Received 5 May 2007; received in revised form 3 August 2007; accepted 7 August 2007

Available online 11 August 2007

\begin{abstract}
Several classes of antifungal have been employed in candidiasis treatment, but patients with advanced immunodeficiency can present unsatisfactory results after therapy. In these cases, high doses of drugs or the use of multiple agents are sometimes used, and hence increasing the risk of serious side effects. Considering theses difficulties, the encapsulation of antifungal agents in nanoparticulate carriers has been used with the objective of modifying the pharmacokinetic of drugs resulting in more efficient treatments with less side effects. The purpose of this work was the preparation, characterization and the investigation of the release profiles of radiolabeled fluconazole nanocapsules. The size, homogeneity and zeta potential of NC preparations were determined with a Zetasizer 3000HS. The morphology and the structural organization were evaluated by atomic force microscopy (AFM). The release study in vitro of NC was evaluated in physiologic solution with or without $70 \%$ mouse plasma. The labeling yield of fluconazole with ${ }^{99 \mathrm{~m}} \mathrm{Tc}$ was $94 \%$ and the radiolabeled drug was stable within $24 \mathrm{~h}$ period. The encapsulation percentage of ${ }^{99 m}$ Tc-fluconazole in PLA-POLOX NC and PLA-PEG NC was approximately of 30\%. The average diameter calculated by photon correlation spectroscopy (PCS) varied from 236 to $356 \mathrm{~nm}$, while the average diameter determined by AFM varied from 238 to $411 \mathrm{~nm}$. The diameter/height relation decreased significantly when $25 \%$ glutaraldehyde was used for NC fixation on mica. The zeta potential varied from -55 to $-69 \mathrm{~nm}$ and surface-modified NC showed lower absolute values than conventional NC. The in vitro release of ${ }^{99 \mathrm{~m}} \mathrm{Tc}$-fluconazole in plasma medium of the conventional and surface-modified NC was greater than in saline. The drug release in plasma medium from conventional NC was faster than for surface-modified NC. The results obtained in this work suggest that the nanocapsules containing fluconazole could be used to identify infectious foci, due to the properties, such as size, zeta potential and controlled release of ${ }^{99 \mathrm{~m}}$ Tc-fluconazole. The surface-modified nanocapsules could constitute a long-circulating intravenous formulation of fluconazole for treating sepsis caused by disseminated form of candidiasis. However, in vivo studies should be considered and are under investigation.
\end{abstract}

(C) 2007 Elsevier B.V. All rights reserved.

Keywords: Nanocapsules; Atomic force microscopy; ${ }^{99 \mathrm{~m}}$ Technetium-fluconazole; Photon correlation spectroscopy; Morphological characterization; Radioactive labeling

\footnotetext{
* Corresponding author. Tel.: +55 3135591638 ; fax: +553135591628.

E-mail address: mosqueira@ ef.ufop.br (V.C.F. Mosqueira).
}

\section{Introduction}

Candida albicans is the most common fungal pathogen, and is the organism responsible for the majority of localized fungal infections in humans (Martin, 1999). Patients with impaired immunity, such as those who have AIDS or are neutropenic as a result of cancer therapy, are at particular risk of developing 
C. albicans infections, which may become systemic. Disseminated infection leading to candidemia can be devastating and cause up to a 60 percent mortality rate in medical or post-surgical intensive care wards (Appleton, 2000).

Several category of antifungal has been used in candidiasis treatment, but the efficacy of therapy depends on precocious diagnosis and immunity of patient. Patients with advanced immunodeficiency can present clinical failure after therapy. In these cases are necessary high doses of drugs and the use of multiple agents, thereby increasing the risk of serious side effects. Despite of these difficulties, the encapsulation of antifungal agents in nanoparticulate carriers can be used with several advantages, such as the possibilities of to restrict access of the drug to the chosen sites and of drug delivering it at a controlled and sustained rate to the desired site, increasing the drug therapeutic efficacy and reducing the side effects. Some antifungal agents have been encapsulated in nanoparticles and promising results has been observed in animal models and in clinical therapy. These studies include mainly the polyenes drugs, represented by amphotericin B and nystatin (Maesaki, 2002; Mehta et al., 1987a,b; Otsubo et al., 1999). There are some few studies about association of azole antifungal with nanoparticles (Chasteigner et al., 1998; Gupta et al., 2000; Agarwal and Katare, 2002).

Previous works have studied and characterized azole antifungal loaded in nanoparticles. The physico-chemical properties of nanoparticles are very important to evaluate the mechanisms of drug-carrier association, the stability, homogeneity and morphology of the formulations. Chasteigner et al. (1998) showed that the itraconazole, a triazole antifungal, yielded greater association efficiencies with chemically modified $\beta$-cyclodextrin nanospheres composed of poly- $\varepsilon$-caprolactone (PCL), and a negatively charged steroidal surfactant, sodium deoxycholate, than with other lipid-based drug carriers, such as liposomes and cholesterol complexes. Molina et al. (2001) studied three azoles antifungals (itraconazole, ketoconazole and DO870) loaded in PLA-PEG nanospheres that showed a monodisperse size distribution between 100 and $200 \mathrm{~nm}$ and efficiency of drug entrapment of 90, 87 and 92\%, respectively. Moreover, the itraconazole was also encapsulated in PLGA nanocapsules, and the concentration of polymer, oil and drug had significant effect on nanocapsules particle size and on the amount of itraconazole entrapped in the nanoparticles (Prakobvaitayakit and Nimmannit, 2003).

A special attention was devoted to the nanocapsules (NC) that are a special type of nanometric colloidal carrier that possesses an oily core surrounded by a polymeric wall, where lipophilic and/or hydrophilic surfactants can be placed at the interface (Legrand et al., 1999). The ability of NC to modify the biopharmaceutical properties of lipophilic substances has been demonstrated before by several authors (Barratt, 2000). The NC generally presents high entrapment efficiency for lipophilic drugs and low polymer content compared to nanospheres in total formulation (Mosqueira et al., 2006). However, conventional nanoparticles are rapidly cleared from the circulation by phagocytes of the mononuclear phagocyte system (MPS) (Gref et al., 1994). Surface modification of nanocapsules with hydrophilic polymers, such as polyethylene- glycol (PEG), resulted in decreased recognition by the MPS, thereby increasing the half-life of their circulation in the blood (Mosqueira et al., 2001b). The fluconazole is a candidate to be entrapped within the oily core of nanocapsules because this drug has low water solubility and a favorable partition coefficient octanol/PBS (McEvoy, 2003). In this way, the aim of the present work was the preparation, characterization and the investigation of the release profiles of nanocapsules prepared with poly-D,L-lactide (PLA) and with the copolymer of monomethoxy-polyethyleneglycol-co-poly-D,L-lactide (PLA-PEG), containing radiolabeled fluconazole, which could further be employed in biodistribution studies.

\section{Materials and methods}

\subsection{Materials}

Soy lecithin (Epikuron ${ }^{\circledR}$ 170) was purchased from Lucas Meyer (France). Poly(D,L-lactic acid) PLA $_{50}$ with an average molecular mass (MW) of 75,000 Da and the surfactant poloxamer 188 (Synperonic ${ }^{\circledR}$ F 68) were provided by Sigma-Aldrich (USA). Miglyol 810N (caprylic/capric triglyceride) was gift from Hulls (Germany). PLA-PEG (PLA of 49,000 Da containing approximately $10 \%$ PEG with a MW of $5000 \mathrm{Da}$ ) was provided by Alkermes (USA) and was used without further purification. The fluconazole was provided by Galena (Brazil) and ${ }^{99 \mathrm{~m}} \mathrm{Tc}$ (pertechnetate form) was obtained as a sodium solution from a ${ }^{99}$ Mo generator (IPEN/Brazil). All the solvents used were analytical grade, and other chemicals were commercially available reagent grade and used without further purification. Water was purified by reverse osmosis (Simplicity 185, Millipore, Bedford, USA).

\subsection{Methods}

\subsubsection{Procedure and efficiency of fluconazole labeling with ${ }^{99 m}$ Technetium}

Fluconazole was labeled according to the method described by Lupetti et al. (2002). In a labeling vial were mixed $50 \mu \mathrm{L}$ of a fluconazole solution $(2 \mathrm{mg} / \mathrm{mL}), 4 \mu \mathrm{L}$ of a solution containing $1 \mathrm{mg} / \mathrm{mL}$ of $\mathrm{SnCl}_{2} \cdot 2 \mathrm{H}_{2} \mathrm{O}$ and $2 \mathrm{mg} / \mathrm{mL}$ of sodium pyrophosphate and $4 \mu \mathrm{L}$ of a solution containing $10 \mathrm{mg} / \mathrm{mL}$ of $\mathrm{KBH}_{4}$ in $0.1 \mathrm{~mol} / \mathrm{L} \mathrm{NaOH}$. After addition of $0.1 \mathrm{~mL}$ of ${ }^{99 \mathrm{~m}} \mathrm{Tc}$-sodium pertechnetate solution $(74 \mathrm{MBq})$, the mixture was gently stirred at room temperature for $120 \mathrm{~min}$ and diluted with $0.01 \mathrm{~mol} / \mathrm{L}$ acetic acid to a final volume of $1 \mathrm{~mL}$. The mixture was applied to a Maxi-Clean $\mathrm{C}_{18}$ cartridge (Alltech Associations, EUA) previously flushed with $20 \mathrm{~mL} 0.01 \mathrm{~mol} / \mathrm{L}$ acetic acid, to remove the radioactive impurities, free pertechnetate and colloids. After being rinsed with $20 \mathrm{~mL}$ acetic acid, ${ }^{99} \mathrm{~m}$ Tc-fluconazole was eluted with $2 \mathrm{~mL}$ methanol which was evaporated using hot air. This procedure was repeated twice. The colloidal radioactivity was entrapped in the cartridge.

The labeling yield and stability of ${ }^{99 \mathrm{~m}} \mathrm{Tc}$-fluconazole were determined using instant thin-layer chromatography (ITLC) with methyl-ethyl-ketone as the eluent. Only ${ }^{99 \mathrm{~m}} \mathrm{Tc}$ in the form of pertechnetate was eluted by this method. The ${ }^{99 \mathrm{~m}} \mathrm{Tc}-$ 
fluconazole remained at the site of origin. The stability of ${ }^{99 \mathrm{~m}} \mathrm{Tc}$-fluconazole was also determined after incubation of $500 \mu \mathrm{L}$ of the solution in $500 \mu \mathrm{L}$ of mouse serum at $37^{\circ} \mathrm{C}$. After 15, 30, 60, 90, 120, 360 and 1440 min, the amounts of free/released pertechnetate were assessed by ITLC as described above. The radioactivity of chromatography strips was determinate in a gamma radiation counter equipped with a $\mathrm{NaI}$ (TI) crystal (ANSR, ABBOT, USA).

\subsubsection{Size-exclusion chromatography analysis}

A $2 \mathrm{~mL}$ volume of radiolabeled fluconazole was applied into a column of Sephadex G150 $(20 \mathrm{~cm} \times 0.6 \mathrm{~cm})$ previously flushed with $20 \mathrm{~mL}$ of phosphate-buffered saline (PBS, pH 7.3). Aliquots of $1 \mathrm{~mL}$ were eluted and the radioactivity was determined in a gamma radiation counter equipped with a $\mathrm{NaI}$ (TI) crystal (ANSR, ABBOT, USA). The same procedure was performed with unlabeled fluconazole $(2 \mathrm{mg} / \mathrm{mL})$ and the eluted aliquots were evaluated by absorbance measurements at $220 \mathrm{~nm}$. The profiles of the two formulations were compared.

\subsubsection{Preparation of nanocapsules}

Conventional nanocapsules (PLA NC) were prepared according to the method described by Fessi et al. (1989) and those sterically stabilized with PEG were prepared using the method reported by Mosqueira et al. (2001a). Poly(D,L-lactic acid) (MW $75,000 \mathrm{Da}$ ) was used together with Poloxamer 188, a surfactant that contains polyethyleneglycol chains in its structure, to prepare conventional NC. In this case, the poloxamer is only adsorbed at the NC surface. Surface-modified NC was prepared using the diblock polymer PLA-PEG (PLA, 49,000 Da and PEG, $5000 \mathrm{Da}$ ) in the absence of poloxamer. Briefly, the polymer $(0.6 \%, \mathrm{w} / \mathrm{v})$ was dissolved in a mixture of methanol acetone (1:3) containing $0.75 \%(\mathrm{w} / \mathrm{v})$ of soy lecithin (Epikuron $\left.{ }^{\circledR} 170\right)$ and $2.5 \%(\mathrm{v} / \mathrm{v})$ of Miglyol $^{\circledR} 810 \mathrm{~N}$. In the case of conventional $\mathrm{NC}$, this organic solution was poured into the external aqueous phase containing $0.75 \%(\mathrm{w} / \mathrm{v})$ of Synperonic ${ }^{\circledR}$ F68 with stirring. The solvents were evaporated to $10 \mathrm{~mL}$ under reduced pressure (Fisatom Rotary Evaporator, Brazil). The NC containing the drug was prepared by the same method with purified ${ }^{99 \mathrm{~m}} \mathrm{Tc}$-fluconazole suspended in a mixture methanol acetone (1:3).

\subsubsection{Determination of ${ }^{99 m} T c$-fluconazole encapsulated in nanocapsules}

The percentage of encapsulation of ${ }^{99 \mathrm{~m}} \mathrm{Tc}$-fluconazole in the nanocapsules was calculated by the difference between the total drug radioactivity in the colloidal suspension and the free ${ }^{99 \mathrm{~m}} \mathrm{Tc}$-fluconazole in the external aqueous phase. The fraction of colloidal suspension in the external phase was assessed by the ultrafiltration/centrifugation method in an AMICON device (Microcon, MWCO 10,000 Da, Millipore ${ }^{\circledR}$ ) centrifuging $200 \mu \mathrm{L}$ of NC suspension at $1800 \times g$ for $15 \mathrm{~min}$. The nonencapsulated ${ }^{99 \mathrm{~m}} \mathrm{Tc}$-fluconazole was found in the ultrafiltrate, and the ${ }^{99 \mathrm{~m}} \mathrm{Tc}$-fluconazole associated with the $\mathrm{NC}$ was retained in the upper compartment of the device. The percentage of radioactivity associated with the $\mathrm{NC}$ was determined by the following Eq. (1):

$(\%$ drug loading $)=\frac{A^{\text {Total }}-A^{\text {ultrafiltrate }}}{A^{\text {Total }}} \times 100$

where $A$ : activity determined in a gamma radiation counter equipped with an NaI (TI) crystal (ANSR, ABBOT, USA).

To obtain purified $\mathrm{NC}$, free of unloaded ${ }^{99 \mathrm{~m}} \mathrm{Tc}$-fluconazole, the method described above was used, and the ${ }^{99 \mathrm{~m}} \mathrm{Tc}-$ fluconazole-loaded NC were then diluted in saline solution. These purified $\mathrm{NC}$ were used in further characterization and release experiments.

\subsection{5. ${ }^{99 m}$ Tc-fluconazole release from nanocapsules}

The ${ }^{99 \mathrm{~m}} \mathrm{Tc}$-fluconazole released from the $\mathrm{NC}$ formulations was determined in saline solution and in $70 \%$ mouse plasma/saline at different times at $37^{\circ} \mathrm{C}$ under sink conditions. In the release experiments, $125 \mu \mathrm{L}$ of $\mathrm{NC}$ suspension was incubated with $500 \mu \mathrm{L}$ of each medium at $37^{\circ} \mathrm{C}$ with moderate stirring. At each point of time chosen, the external phase was separated from the total NC suspension by the ultrafiltration/centrifugation technique in Ultrafree ${ }^{\circledR}$ units with a $0.1 \mu \mathrm{m}$ pore size (Millipore ${ }^{\circledR}$ ) that allowed the filtration of serum proteins. In this method, $400 \mu \mathrm{L}$ of medium with $\mathrm{NC}$ suspension was added to the upper compartment of the device, and it was centrifuged at $1800 \times g$ for $15 \mathrm{~min}$. The separation membrane used in this study allowed the elution of the free ${ }^{99 \mathrm{~m}} \mathrm{Tc}$-fluconazole or that associated with plasmatic protein, while the NC remained in the compartment above the ultrafiltration membrane. This analysis was evaluated in time periods of up to $240 \mathrm{~min}$. The percentage of radioactivity released from $\mathrm{NC}$ was determined from following Eq. (2), where A: activity determined in a gamma radiation counter (ANSR, ABBOT, USA).

$(\%$ drug release $)=\frac{A^{\text {ultrafiltrate }}}{A^{\text {Total }}} \times 100$

\subsubsection{Characterization of the nanocapsules}

2.2.6.1. Photon correlation spectroscopy analysis. The mean size of the nanocapsules was determined by photon correlation spectroscopy. This method allows the determination of the mean diameter of the particle and the polydispersity index (PI), which is a dimensionless measure of the broadness of the particle size distribution. Particle size was evaluated in a Zetasizer HS3000 (Malvern Instruments, Malvern, UK). Samples were analyzed after appropriate dilution in ultra-pure Milli-Q water. Reported values were expressed as mean \pm standard deviation for ten different batches of each nanocapsule formulation.

2.2.6.2. Atomic force microscopy imaging. AFM observation was performed in air at room temperature, on a Dimension 3000 apparatus, as well as on Multimode Equipment, both monitored by a Nanoscope IIIa controller from Digital Instruments (Santa Barbara, CA, USA). A droplet $(5 \mu \mathrm{L})$ of sample was deposited on a freshly cleaved mica surface, spread and dried with a stream of argon. Another method of sample fixation on mica surface was evaluated: a droplet $(5 \mu \mathrm{L})$ of $25 \%$ glu- 
Table 1

Composition of NC preparations

\begin{tabular}{|c|c|c|c|c|c|c|}
\hline $\mathrm{NC}$ formulation & Polymer (molar ratio) & Polymer $(\%, w / v)$ & POLOX $(\%, w / v)$ & Lecithin $(\%, \mathrm{w} / \mathrm{v})$ & Miglyol (\%,w/v) & FLU $(\mathrm{mg} / \mathrm{mL})$ \\
\hline PLA-POLOX & $\mathrm{PLA}_{50}$ & 0.6 & 0.75 & 0.75 & 2.5 & - \\
\hline PLA-PEG & $\mathrm{PLA}_{50}-\mathrm{PEG} 49-5^{\mathrm{a}}$ & 0.6 & - & 0.75 & 2.5 & - \\
\hline${ }^{99 m}$ Tc-FLU-PLA-POLOX & $\mathrm{PLA}_{50}$ & 0.6 & 0.75 & 0.75 & 2.5 & + \\
\hline${ }^{99 m}$ Tc-FLU-PLA-PEG & $\mathrm{PLA}_{50}-\mathrm{PEG} 49-5^{\mathrm{a}}$ & 0.6 & - & 0.75 & 2.5 & + \\
\hline FLU-PLA-POLOX & $\mathrm{PLA}_{50}$ & 0.6 & 0.75 & 0.75 & 2.5 & 2 \\
\hline FLU-PLA-PEG & $\mathrm{PLA}_{50}-\mathrm{PEG} 49-5^{\mathrm{a}}$ & 0.6 & - & 0.75 & 2.5 & 2 \\
\hline
\end{tabular}

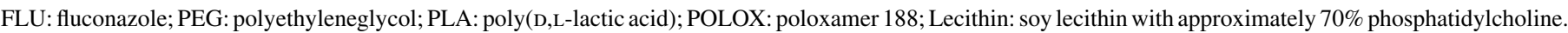

a Formulations containing approximately $10 \%$ PEG.

taraldehyde was deposited on a freshly cleaved mica surface before deposition of the NC sample. After applying the sample, the liquids were mixed and dried with a stream of argon. The images were obtained in tapping mode, using commercial silicon probes from Nanosensors ${ }^{\mathrm{TM}}$, with cantilevers having a length of $228 \mu \mathrm{m}$, resonance frequencies of 75-98 kHz, spring constants of $29-61 \mathrm{~N} / \mathrm{m}$ and a nominal tip curvature radius of $5-10 \mathrm{~nm}$. The scan rate used was $1 \mathrm{~Hz}$. Dimensional analyses were performed using the "section of analyses" program of the system. A minimum of ten images from each sample was analyzed to assure reproducible results. The values represent an average \pm standard deviation of approximately 40 particle measurements.

2.2.6.3. Zeta potential analyses. The zeta potential was evaluated by Laser Doppler Electrophoresis (LDE) measurements in a Zetasizer HS3000 (Malvern Instruments, Malvern, UK). The samples were analyzed following dilution by $1: 1000$ in $1 \mathrm{mM}$ $\mathrm{NaCl}$ at a conductivity of approximately $120 \pm 20 \mathrm{mS} / \mathrm{cm}^{2}$. Values reported are the mean \pm standard deviation of at least three different batches of each nanocapsule formulation.

\subsubsection{Statistics}

All experiments were performed in triplicate and were expressed as mean values \pm standard deviations, unless otherwise stated. Mean sizes, zeta potential and drug release data at each time point were compared by an ANOVA test using the Prism 4.0 program while considering a probability of $5 \%$ to be significant.

\section{Results and discussion}

NC containing ${ }^{99 m}$ Tc-fluconazole were prepared by the interfacial deposition of the preformed polymer followed by solvent evaporation, a simple and rapid method of obtaining nanocapsules suitable for intravenous administration. Two types of nanocapsules containing ${ }^{99 \mathrm{~m}} \mathrm{Tc}$-fluconazole were developed in this work: conventional PLA NC and surface-modified PLAPEG NC. The composition of NC is summarized in Table 1. Surface-modified nanocapsules (PLA-PEG NC) were included in this study because their uptake by the mononuclear phagocyte system is substantially delayed, thereby increasing the time during which they circulate in the blood stream (Mosqueira et al., 2001b).
Table 2

${ }^{99} \mathrm{TcO}_{4}{ }^{-}$released after incubation of ${ }^{99 \mathrm{~m}} \mathrm{Tc}$-fluconazole with mouse serum

\begin{tabular}{rl}
\hline Time (min) & $\%{ }^{99 \mathrm{~m} \mathrm{TcO}_{4}{ }^{-}}$ \\
\hline 0 & $5.54 \pm 1.20^{\mathrm{a}}$ \\
15 & $5.83 \pm 1.17^{\mathrm{a}}$ \\
30 & $5.72 \pm 0.70^{\mathrm{a}}$ \\
60 & $6.62 \pm 1.36^{\mathrm{a}}$ \\
90 & $6.07 \pm 1.23^{\mathrm{a}}$ \\
120 & $7.15 \pm 1.64^{\mathrm{a}}$ \\
360 & $6.28 \pm 1.26^{\mathrm{a}}$ \\
1440 & $5.91 \pm 1.42^{\mathrm{a}}$ \\
\hline
\end{tabular}

The results represent the mean \pm standard deviation $(n=4)$ for each determination.

a Identical letters indicate that there is no significant difference between the data presented $(P>0.05)$.

\subsection{Labeling yield of fluconazole with ${ }^{99 m}$ Technetium}

After the purification process, 94\% of the radioactivity was associated with ${ }^{99 \mathrm{~m}}$ Tc-fluconazole. The results of stability studies of $99 \mathrm{mTc}$-fluconazole in mouse serum for $24 \mathrm{~h}$ at $37^{\circ} \mathrm{C}$ did not show a significant increase in ${ }^{99} \mathrm{TcO}_{4}{ }^{-}$ release $(P>0.05)$ as determined by ITLC (Table 2$)$. These results showed that ${ }^{99 \mathrm{~m}} \mathrm{Tc}$-fluconazole is a stable molecule in the presence of serum components, and it proved to be suitable for use in biodistribution studies. Furthermore, the elution profile of ${ }^{99 \mathrm{~m}} \mathrm{Tc}$-fluconazole by size-exclusion chromatography in Sephadex G150 showed a radioactivity peak coincident with unlabeled fluconazole, between 5 and $9 \mathrm{~mL}$, detected by absorbance measurement at $220 \mathrm{~nm}$ (Fig. 1). These results con-

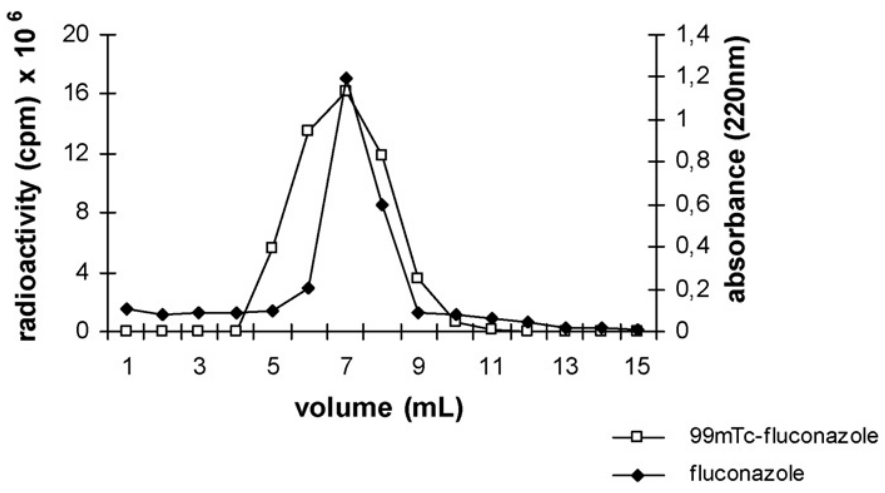

Fig. 1. Chromatography profile of ${ }^{99 \mathrm{~m}} \mathrm{Tc}$-fluconazole and unlabeled fluconazole on Sephadex G150. 
Table 3

Characteristics of the NC preparations

\begin{tabular}{|c|c|c|c|c|c|}
\hline $\mathrm{NC}$ formulation & $\begin{array}{l}\text { Mean size } \pm \text { S.D. }^{\mathrm{a}} \\
(\mathrm{nm}) \\
\mathrm{PCS}\end{array}$ & $\begin{array}{l}\text { Mean size } \pm \text { S.D. } \\
(\mathrm{nm}) \\
\text { AFM }\end{array}$ & $\begin{array}{l}\text { Mean size } \pm \text { S.D. }^{\mathrm{b}} \\
(\mathrm{nm})^{\mathrm{c}} \\
\text { AFM (glut.) }\end{array}$ & $\begin{array}{l}\text { Polydispersity } \\
\text { index }\end{array}$ & $\begin{array}{l}\zeta \text { Potential } \pm \text { S.D. } \\
(\mathrm{mV})^{\mathrm{e}}\end{array}$ \\
\hline PLA-POLOX & $282 \pm 24$ & $411 \pm 128$ & $193 \pm 26$ & $0.340^{\mathrm{f}}$ & $-69.6 \pm 8.4$ \\
\hline${ }^{99 m}$ Tc-Fluconazole-PLA-POLOX & $356 \pm 45$ & $298 \pm 151$ & $200 \pm 40$ & $0.375^{\mathrm{f}}$ & $-66.2 \pm 6.7$ \\
\hline${ }^{99 \mathrm{~m}}$ Tc-Fluconazole-PLA-PEG & $351 \pm 24$ & $264 \pm 95$ & $202 \pm 45$ & $0.418^{\mathrm{f}}$ & $-55.4 \pm 7.8$ \\
\hline Fluconazole-PLA-POLOX & $347 \pm 15$ & nd & nd & $0.116^{\mathrm{g}}$ & $-62.3 \pm 1.6$ \\
\hline
\end{tabular}

nd: not determined

a Standard deviation of measurements from 10 different batches.

b Standard deviation of size measurements of 40 nanocapsules.

c Samples fixed with $25 \%$ glutaraldehyde.

d Standard deviation of at least three measurements obtained from different batches.

e Measurement after 1:1000 dilution in $1 \mathrm{mM} \mathrm{NaCl}$ (conductivity, $120 \pm 20 \mu \mathrm{S} / \mathrm{cm}$ ).

${ }^{\text {f }}$ Homogeneous samples $(\leq 0.5)$.

g Monodispersed samples $(\leq 0.3)$.

firmed the chemical integrity of fluconazole molecule after the radiolabeling process. Free pertechnetate and colloids represented less than $6 \%$ of the total radioactivity in the labeling solution. The fluconazole labeling yield obtained in the present work are in agreement with those previously published by Lupetti et al. (2002).

\subsection{Nanocapsule characterization}

The percentage of encapsulation was $29.3 \pm 3.5$ and $32.2 \pm 1.5 \%$ for PLA NC and PLA-PEG NC preparations, respectively. The nature of the polymer, PLA or PLA-PEG, did not modify the percentage of ${ }^{99 \mathrm{~m}} \mathrm{Tc}$-fluconazole encapsulated $(P>0.05)$.

The particle size, polydispersity index and zeta potential of prepared conventional and surface-modified NC containing ${ }^{99 \mathrm{~m}} \mathrm{Tc}$-fluconazole are presented in Table 3 . The mean size and size distribution of the nanoparticles have a key role in determining their fate following administration, their interaction with the cell membrane and their penetration across the physiological drug barriers (Feng et al., 2004). Some authors have demonstrated that the mean diameter of nanoparticles has an influence on the biodistribution studies because large particles are rapidly taken up by MPS, thereby reducing their half-lives in the circulatory system (Owens and Peppas, 2006). The polydispersity index is indicative of the size distribution, and it showed that the different $\mathrm{NC}$ formulations prepared by the nanoprecipitation method were homogeneous $(\mathrm{PI}<0.5)$. However only fluconazole-loaded $\mathrm{NC}$ were monodisperse $(\mathrm{PI} \leq 0.3)$. The particle size of this formulation was the most homogeneous even when compared with the unloaded PLA and PLA-PEG NC. The mean size of NC obtained in this study $(236-356 \mathrm{~nm})$ are in agreement with data obtained by others authors that observed NC diameters between 200 and $300 \mathrm{~nm}$ (Couvreur et al., 2002; Mosqueira et al., 2006). Torchilin (2000) showed that nanoparticles ranging from 10 to $500 \mathrm{~nm}$ in size can extravasate and accumulate in areas with increased vascular permeability. Therefore, the NC sizes obtained in this study are suitable for reaching infectious and inflammatory foci. It seems that the introduction of fluconazole in the NC composition increases the particle size. The mean diameters of unloaded NC were smaller than NC containing ${ }^{99 \mathrm{~m}} \mathrm{Tc}$-fluconazole or unlabeled fluconazole $(P<0.05)$. The interaction of fluconazole with phospholipid bilayers has previously been investigated (Pascual et al., 1993; Ambrosini et al., 1998), and it could be one of the reasons for the effect observed in this work because all $\mathrm{NC}$ formulations contained a high percentage of phosphatidylcholine. Ambrosini and co-workers have suggested that fluconazole interacts with the polar head group region without penetration into the apolar hydrocarbon region of bilayers.

Zeta potential results (Table 3) showed that the unloaded $\mathrm{NC}$ and $\mathrm{NC}$ containing radiolabeled and unlabeled fluconazole exhibited a negative charge with values ranging from -55.4 to $-69.6 \mathrm{mV}$, as is typically observed for these types of systems composed of PLA polymer (Mosqueira et al., 2001a). The presence of PEG resulted in a reduction in absolute values of the zeta potential for unloaded $\mathrm{NC}$ and NC containing ${ }^{99 \mathrm{~m}} \mathrm{Tc}$-fluconazole $(P<0.05)$. Previous studies showed that formulations with PEG chains have a reduced zeta potential when compared with conventional nanoparticles (Fresta et al., 2001; Mosqueira et al., 2001b; Ameller et al., 2004; Faria et al., 2005). According to Mosqueira et al. (2006), the reduction of the zeta potential is a result of the presence of the PEG layer at NC surface that shifts the plane of shear to the outer boundary of the layer, thereby masking the real zeta potential value. Although the PLA-PEG $\mathrm{NC}$ showed reduced zeta potential, the absolute values are still high compared with previously reported zeta potential for PLAPEG nanospheres (Gref et al., 1994). It was demonstrated that lecithin in the nanocapsules formulation contributed to the maintenance of the high negative surface charge masking the effects of PEG chains in the zeta potential measurements (Mosqueira et al., 2001a). However, in vivo the same amount of PEG at the NC surface increases eight fold the AUC (plasma) in mice (Mosqueira et al., 2001b).

The images produced by the AFM technique are threedimensional, with a high resolution in the nanometrical scale 


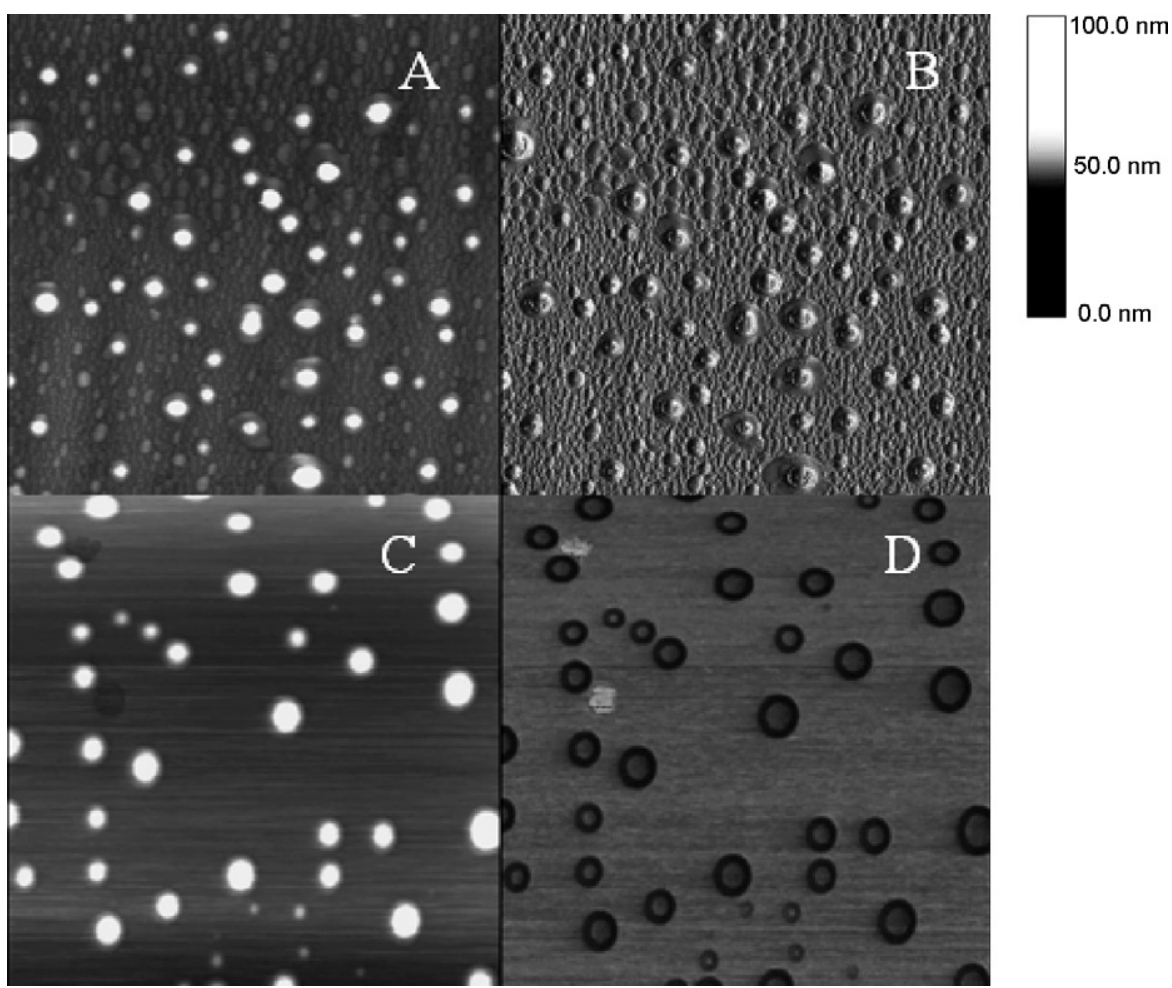

Fig. 2. AFM images of height (A and C) and phase (B and D) of PLA-POLOX NC containing ${ }^{99 \mathrm{~m}}$ Tc-fluconazole (upper images) and of PLA-PEG NC containing ${ }^{99 \mathrm{~m}} \mathrm{Tc}$-fluconazole (lower images) showing spherical nanostructures. Scan size: $5 \mu \mathrm{m} \times 5 \mu \mathrm{m}$.

(Neves et al., 1998). In this technique, the preparation of the sample is very simple. It is deposited in a partially dried state onto freshly cleaved mica plates, a fact that allows simultaneous characterization of particle shape, structure and interparticle organization. All nanocapsule preparations presented a spherical form in the AFM images (Figs. 2 and 3). The NC presented a heterogeneous distribution in size and height in three-dimensional images (Fig. 3). The PLA-POLOX nanocapsules (Fig. 2A and B) presented more complex images than those obtained with

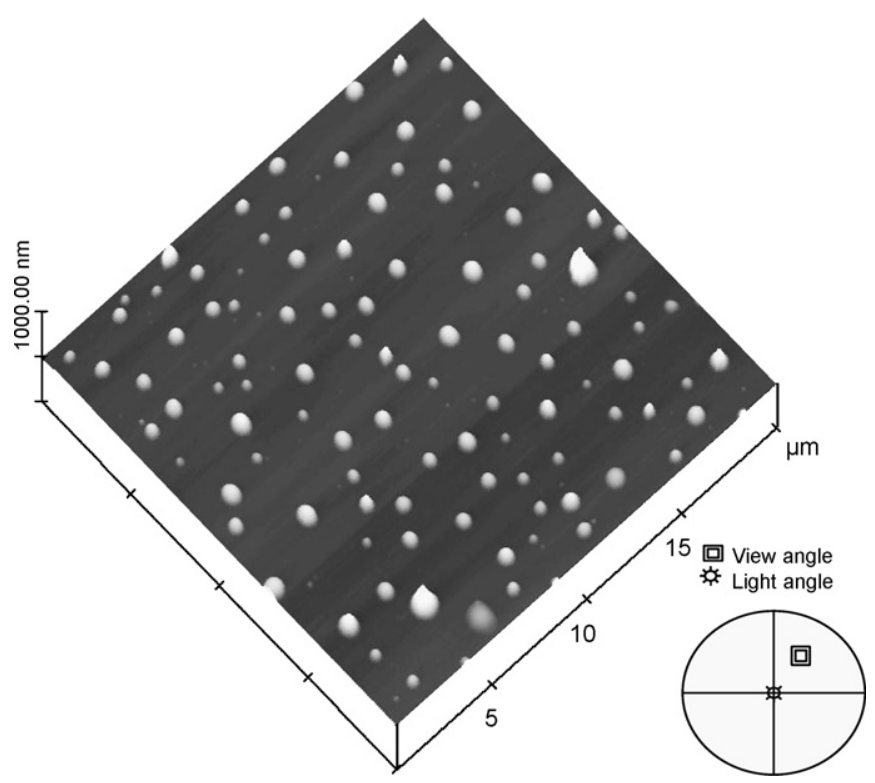

Fig. 3. Three-dimensional AFM image of height of PLA-POLOX NC.
PLA-PEG (Fig. 2C and D) because they had few nanometer layers $(2-10 \mathrm{~nm})$ with different heights, probably because the presence of lecithin and poloxamer. On the other hand, PLAPEG NC (Fig. 2C and D), without poloxamer, presented more homogeneous particles that were less contaminate by layers. The average size of unloaded conventional NC obtained by AFM were $411 \pm 128 \mathrm{~nm}$, while those containing ${ }^{99 \mathrm{~m}} \mathrm{Tc}$-fluconazole were $298 \pm 151 \mathrm{~nm}(n=40)$. However, these differences were not significant, in contrast to the results observed by PCS. The average diameter calculated was $238 \pm 124 \mathrm{~nm}(n=40)$ for unloaded PLA-PEG NC and $264 \pm 95 \mathrm{~nm}(n=40)$ for PLAPEG NC containing ${ }^{99 \mathrm{~m}} \mathrm{Tc}$-fluconazole. The mean sizes were not significantly different $(P>0.05)$. However, the variation in diameters represented by the standard deviation of measurements obtained by AFM was larger than those measured by PCS for both NC types. This observation can be explained as a possible NC flattening and aggregation process that takes place after drying on a mica surface. In fact, the flattening phenomenon was probably related to variations in polymeric wall thickness and in its homogeneity (Leite et al., 2005).

The diameter/height ratios were calculated from the topographical profile (Table 4). The values showed a ratio of approximately 11 for both types of unloaded NC. These results confirmed the existence of flattened forms that were also suggested by Montasser et al. (2002) who worked with nanocapsules prepared with the co-polymer dichlorophthaloylco-diethylenetriamine and observed a diameter/height ratio of 12. Similarly, Leite et al. (2005) observed a ratio of approximately 10 for poly- $\varepsilon$-caprolactone NC. The diameter/height ratios observed in the present study were very similar, con- 
Table 4

Diameter/height ratios of nanocapsules analyzed by AFM

\begin{tabular}{lll}
\hline NC formulation & \multicolumn{2}{l}{ Diameter/height ratio \pm S.D. ${ }^{\mathrm{a}}$} \\
\cline { 2 - 3 } & $\begin{array}{l}\text { Not fixed with } \\
\text { glutaraldehyde }\end{array}$ & $\begin{array}{l}\text { Fixed with } \\
\text { glutaraldehyde }\end{array}$ \\
\hline PLA-POLOX & $11.1 \pm 1.1$ & $1.7 \pm 0.5$ \\
PLA-PEG & $11.0 \pm 2.6$ & $6.1 \pm 2.3$ \\
${ }^{99 \mathrm{~m}}$ Tc-Fluconazole-PLA-POLOX & $16.6 \pm 3.6$ & $2.2 \pm 0.6$ \\
${ }^{99 m}$ Tc-Fluconazole-PLA-PEG & $15.4 \pm 3.0$ & $6.0 \pm 1.6$ \\
\hline
\end{tabular}

${ }^{\text {a }}$ Standard deviation of 40 measurement.

firming the flattening process during AFM analysis. When the ${ }^{99 \mathrm{~m}}$ Tc-fluconazole was associated with the NC, the diameter/height ratios increased to values of 15.4 and 16.6 for ${ }^{99 \mathrm{~m}}$ Tc-fluconazole-PLA-POLOX and ${ }^{99 \mathrm{~m}}$ Tc-fluconazole-PLAPEG NC, respectively (Table 4). These NC were evaluated by AFM, 24 and $48 \mathrm{~h}$ after deposition on the mica surface, as is shown in detail in Fig. 4. The observations demonstrated the occurrence of an aggregation process and flattening phenomena on mica that caused a fusion of $\mathrm{NC}$ and, consequently, an increase in $\mathrm{NC}$ sizes after $48 \mathrm{~h}$. NC containing ${ }^{99 \mathrm{~m}} \mathrm{Tc}$ - fluconazole showed more pronounced flattening phenomena in the samples when compared with unloaded NC, probably due to increased complexity on $\mathrm{NC}$ wall formation in the presence of the radiolabeled drug. On the other hand, this aggregation process was not observed when $25 \%$ glutaraldehyde was used on the mica surface (Fig. 5), suggesting that nanocapsules maintained their structures unaltered $48 \mathrm{~h}$ after the deposition. Furthermore, the diameter/height ratio obtained for NC fixed with $25 \%$ glutaraldehyde (Table 4 ) decreased significantly to 1.7 and 6.1 for unloaded PLA-POLOX NC and PLA-PEG NC, respectively. The same process occurred with $\mathrm{NC}$ containing ${ }^{99 m}$ Tc-fluconazole, where the values were reduced to 2.2 and 6 for PLA-POLOX NC and PLA-PEG NC, respectively (Table 4). The greater ratio founded for PLA-PEG NC, despite of drug association, indicate that PEG located on NC surface probably induces a lower degree of NC wall interaction with glutaraldehyde. Thus, these observations suggest that the fixation of NC containing radiolabeled fluconazole on the mica surface by glutaraldehyde could be an important method in sample preparation for AFM analysis. The glutaraldehyde seems to reduce the flattening process by hardening the wall of the NC and thus preserving its shape and morphology. This sample treatment

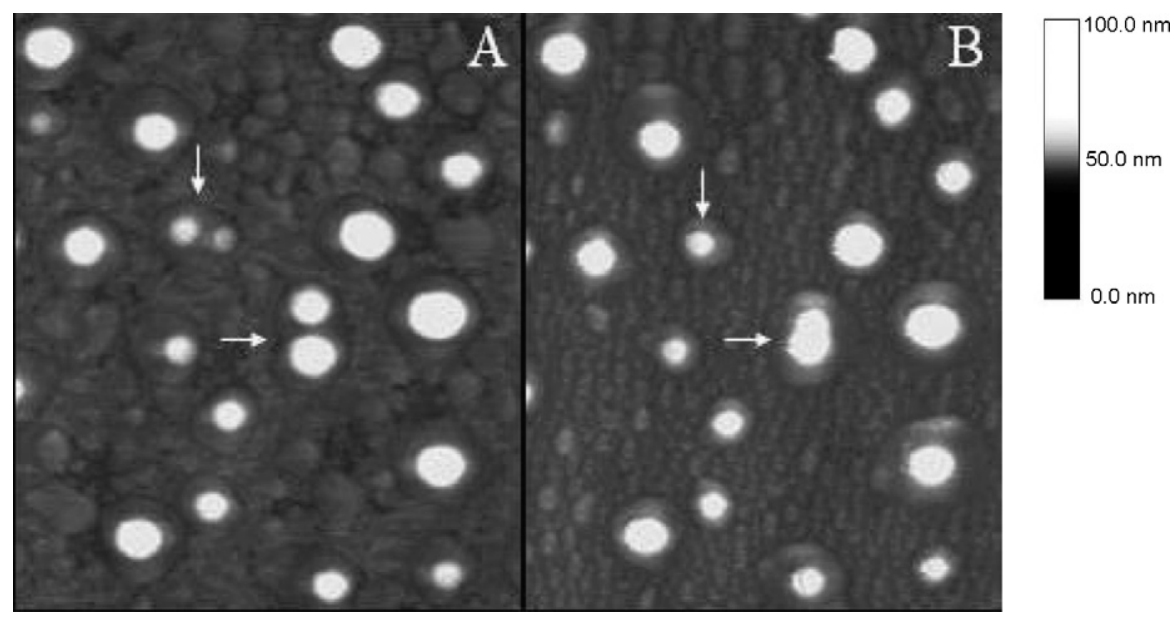

Fig. 4. AFM images of height of PLA-POLOX NC containing ${ }^{99 \mathrm{~m}} \mathrm{Tc}$-fluconazole, $24 \mathrm{~h}$ (A) and $48 \mathrm{~h}$ (B) after deposition of formulation on the mica surface. The white arrows indicate the aggregation of NC. Scan size $5 \mu \mathrm{m} \times 5 \mu \mathrm{m}$.

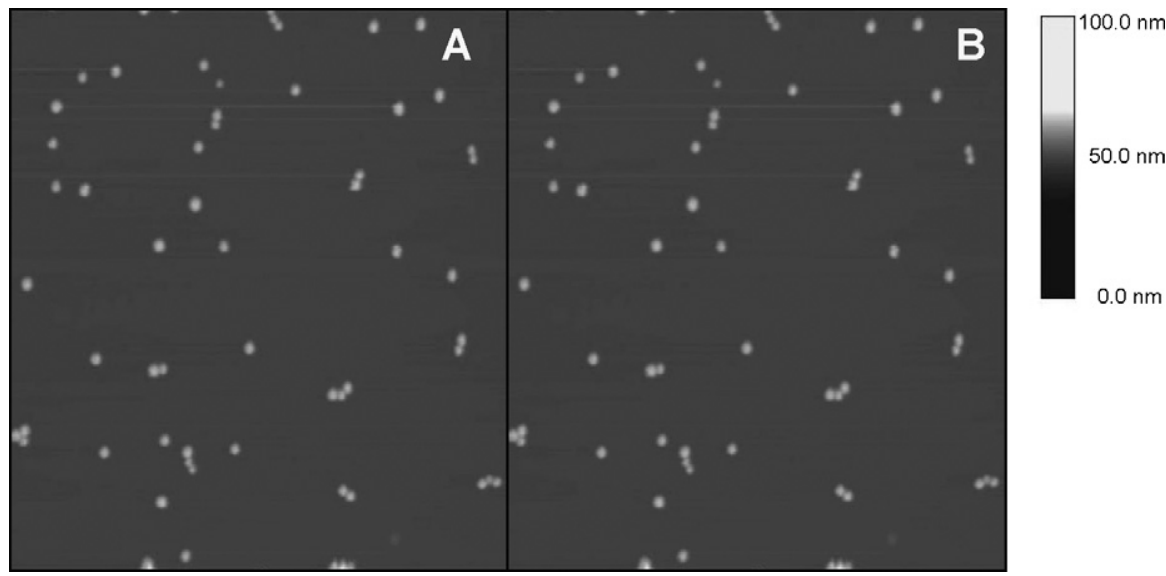

Fig. 5. AFM images of height of PLA-POLOX NC containing ${ }^{99 \mathrm{~m}}$ Tc-fluconazole previously fixed with $25 \%$ glutaraldehyde, $24 \mathrm{~h}$ (A) and $48 \mathrm{~h}$ (B) after deposition of the formulation on the mica plates. Scan size $20 \mu \mathrm{m} \times 20 \mu \mathrm{m}$. 


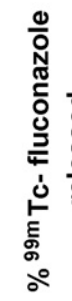

옳
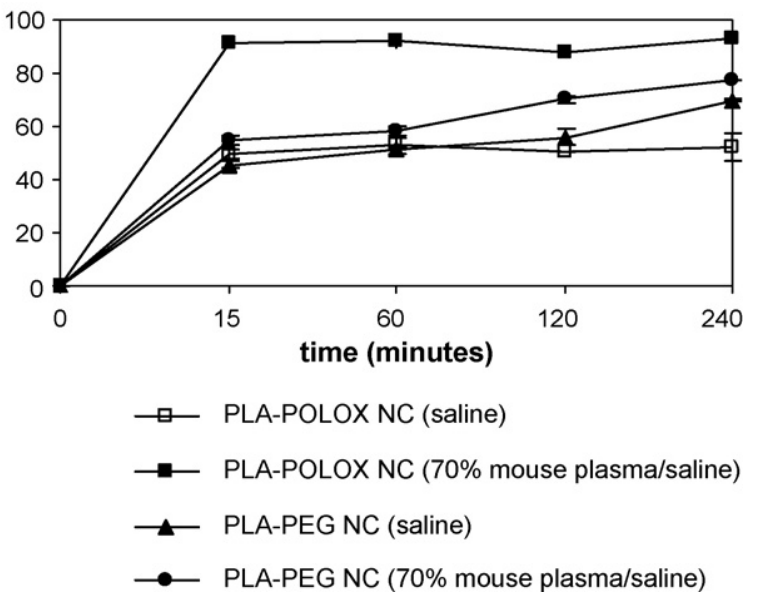

Fig. 6. Release profile of ${ }^{99 \mathrm{~m}} \mathrm{Tc}$-fluconazole from PLA and PLA-PEG NC in saline or saline with $70 \%$ of mouse plasma at $37^{\circ} \mathrm{C}$.

furnished information that more closely approximated the real NC size and morphology.

\section{3. ${ }^{99 m} T c$-fluconazole release from nanocapsules}

The profiles for in vitro release of ${ }^{99 \mathrm{~m}} \mathrm{Tc}$-fluconazole from PLA and PLA-PEG nanocapsules are shown in Fig. 6. The experiments were preformed under sink conditions to avoid the interference of the solubility of the drug with the in vitro release. A fast release of radioactivity for all NC types was observed in the first $15 \mathrm{~min}$. A fast release of drug in the first few minutes after dilution in release media has been interpreted by several authors as drug adsorbed at the NC surface (Schaffazick et al., 2003; Mosqueira et al., 2006). However, plasma protein probably acts as a driving force that promotes ${ }^{99 \mathrm{~m}} \mathrm{Tc}$-fluconazole desorption from the $\mathrm{NC}$ surface as a result of its binding capacity, which removes drug from bulk solution and thus maintains the concentration gradient (Mosqueira et al., 2006). Therefore, the release of ${ }^{99 \mathrm{~m}} \mathrm{Tc}$-fluconazole by PLA-POLOX and PLAPEG NC was greater in the plasmatic medium. In this medium, it was possible to distinguish differences between the two formulations. The drug release by PLA-PEG NC was significantly smaller at all times studied $(P<0.05)$. The PEG layer around the $\mathrm{NC}$ probably reduced the amount of drug released by impairing protein binding at NC surface, such as also observed by Gref et al. (1995) and Mosqueira et al. (2006).

After the immediate release of ${ }^{99 \mathrm{~m}} \mathrm{Tc}$-fluconazole by PLAPOLOX NC, a plateau was observed, indicating no further additional release of effectively encapsulated drug. The polymeric wall of PLA was not able to control release of the drug, which would explain the fast, although incomplete release from PLA-POLOX NC. Furthermore, previous studies suggest that the poloxamer could increase the amount of drug release from NC (Mosqueira et al., 2006). On the other hand, the PLA-PEG $\mathrm{NC}$ showed different biphasic release profile, with the initial burst and after a gradual and incomplete drug release up to $240 \mathrm{~min}$, in plasma and saline media. Those release profiles of ${ }^{99 \mathrm{~m}} \mathrm{Tc}$-fluconazole from $\mathrm{NC}$ indicate that PLA-PEG NC show different properties of drug release control compared with PLA-
POLOX NC. These differences could be attributed to the form of PEG or poloxamer association to the NC surface, by covalent grafting (PLA-PEG) or by adsorption (PLA-POLOX).

Finally, the results indicate that PLA-PEG NC offered advantageous properties as a delivery system of ${ }^{99 \mathrm{~m}} \mathrm{Tc}$-fluconazole over PLA-POLOX formulation, because they show a reduction in drug release as a result of the minor interaction with plasma proteins. These data are in agreement with the studies of Mosqueira et al. (2006), where a better ability to retain and release a lipophilic antimalarial drug was observed with PLA-PEG NC when compared with PLA NC stabilized with poloxamer in media containing plasma.

\section{Conclusion}

Both types of nanocapsule preparations studied in this work were able to encapsulate the ${ }^{99 \mathrm{~m}} \mathrm{Tc}$-fluconazole with the same yield. The homogeneity, the adequate sizes and the negative zeta potential of both types of nanocapsules containing ${ }^{99 \mathrm{~m}} \mathrm{Tc}$ fluconazole indicate that these formulations could be used for reaching infectious foci, such as those induced by $\mathrm{Can}$ dida albicans. Moreover, the presence of covalently grafted PEG chains at the surface provides a hydrophilic steric barrier, limiting and controlling the release of ${ }^{99 \mathrm{~m}} \mathrm{Tc}$-fluconazole. Therefore, it is expected that in further in vivo studies, the PLAPEG nanocapsules containing fluconazole would constitute in a long-circulating intravenous formulation for treating Candida infections.

\section{Acknowledgments}

The authors thank the financial support of FAPEMIG/ NANOBIOMG Network for this study (EDT-1806/02 grant). The authors would like to thank Maira Alves Pereira for her important collaboration.

\section{References}

Agarwal, R., Katare, O.P., 2002. Preparation and in vitro evaluation of miconazole nitrate-loaded topical liposomes. Pharm. Technol. 26, 48-60.

Ambrosini, A., Bossi, G., Dante, S., Dubini, B., Gobbi, L., Leone, L., Bossi, M.G.P., Zolese, G., 1998. Lipid-drug interaction: thermodynamic and structural effects of antimicotic fluconazole on DPPC liposomes. Chem. Phys. Lipids 95, 37-47.

Ameller, T., Marsaud, V., Legrand, P., Gref, R., Renoir, J.-M., 2004. Pure antiestrogen RU 58668-loaded nanospheres: morphology, cell activity and toxicity studies. Eur. J. Pharm. Sci. 21, 361-370.

Appleton, S.S., 2000. Candidiasis: pathogenesis, clinical characterisitics, and treatment. J. Can. Dent. Assoc. 28, 942-948.

Barratt, G., 2000. Therapeutic applications of colloidal drug carriers. Pharm. Sci. Technol. Today 3, 163-171.

Chasteigner, S., Fessi, H., Devissaguet, J.-P., Puisieux, F., 1998. Comparative study of the association of itraconazole with colloidal drug carriers. Drug Dev. Res. 38, 125-133.

Couvreur, P., Barratt, G., Fattal, E., Legrand, P., Vauthier, C., 2002. Nanocapsule technology: a review. Crit. Rev. Drug Carrier Syst. 19, 99-134.

Faria, T.J., Campos, A.M., Senna, E.L., 2005. Preparation and characterization of poly(D,L-lactide) (PLA) and poly(D,L-lactide)-poly(ethylene glycol) (PLAPEG) nanocapsules containing antitumoral agent methotrexate. Macromol. Symp. 229, 228-233. 
Feng, S.S., Li, M., Khin, W., Guofeng, H., 2004. Nanoparticles of biodegradable polymers for clinical administration of paclitaxel. Curr. Med. Chem. 11, 413-424.

Fessi, H., Puisieux, F., Devissaguet, J.-P., Ammoury, N., Benita, S., 1989. Nanocapsule formation by interfacial polymer deposition following solvent displacement. Int. J. Pharm. 55, R1-R4.

Fresta, M., Fontana, G., Bucolo, C., Cavallaro, G., Giammona, G., Puglisi, G., 2001. Ocular tolerability and in vivo bioavailability of poly(ethylene glycol) (PEG)-coated polyethyl-2-cyanoacrylate nanosphere-encapsulated acyclovir. J. Pharm. Sci. 90, 288-297.

Gref, R., Domb, A., Quellec, P., Blunk, T., Muller, R.H., Verbavatz, J.M., Langer, R., 1995. The controlled intravenous delivery of drugs using PEG-coated sterically stabilized nanospheres. Adv. Drug Deliv. Rev. 16, 215-233.

Gref, R., Minamitake, Y., Peracchia, M.T., Trubetskoy, V., Torchilin, V., Langer, R., 1994. Biodegradable long-circulating polymeric nanospheres. Science 263, 1600-1603.

Gupta, S.K., Dhingra, N., Velpandian, T., Jaiswal, J., 2000. Efficacy of fluconazole and liposome entrapped fluconazole for C. albicans induced experimental mycotic endophthalmitis in rabbit eyes. Acta Ophthalmol. Scand. 78, 448.

Legrand, P., Barratt, G., Mosqueira, V., Fessi, H., Devissaguet, J.P., 1999. Polymeric nanocapsules as drug delivery systems: a review. S.T.P. Pharm. Sci. 9, 411-418.

Leite, E.A., Vilela, J.M.C., Mosqueira, V.C.F., Andrade, M.S., 2005. Poly-caprolactone nanocapsules morphological features by atomic force microscopy. Microsc. Microanal. 11, 48-51.

Lupetti, A., Welling, M.M., Mazzi, U., Nibbering, P.H., Pauwels, E.K.J., 2002. Technetium-99m labeled fluconazole and antimicrobial peptides for imaging of Candida albicans and Aspergillus fumigatus infections. Eur. J. Nucl. Med. $29,674-679$.

Maesaki, S., 2002. Drug delivery system of anti-fungal and parasitic agents. Curr. Pharm. Des. 8, 433-440.

Martin, M.V., 1999. The use of fluconazole and itraconazole in the treatment of Candida albicans infections: a review. J. Antimicrob. Chemother. 44, 429-437.

McEvoy, G.K., 2003. Antifungal antibiotics-fluconazole. In: McEvoy, G.K. (Ed.), AHFS Drug Information. American Society of Health System Pharmacists Inc., Bethesda, MD, p. 101.

Mehta, R.T., Hopfer, R.L., Gunner, L.A., Juliano, R.L., Lopez-Berestein, G., 1987a. Formulation, toxicity, and antifungal activity in vitro of liposome-encapsulated nystatin as therapeutic agent for systemic candidiasis. Antimicrob. Agents Chemother. 31, 1897-1900.
Mehta, R.T., Hopfer, R.L., McQueen, T., Juliano, R.L., Lopez-Berestein, G., 1987b. Toxicity and therapeutic effects in mice of liposome-encapsulated nystatin for systemic fungal infections. Antimicrob. Agents Chemother. 31, 1901-1903.

Molina, J., Urbina, J., Gref, R., Brener, Z., Junior, J.M.R., 2001. Cure of experimental Chagas's disease by the bis-triazole DO870 incorporated into stealth polyethyleneglycol-polylactide nanospheres. Antimicrob. Agents Chemother. 47, 101-104.

Montasser, I., Fessi, H., Coleman, A.W., 2002. Atomic force microscopy imaging of novel type of polymeric colloidal nanostructures. Eur. J. Pharm. Biopharm. 54, 281-284.

Mosqueira, V.C.F., Legrand, P., Barratt, G., 2006. Surface-modified and conventional nanocapsules as novel formulation for parenteral delivery of halofantrine. J. Nanosci. Nanotechnol. 9-10, 3193-3202.

Mosqueira, V.C.F., Legrand, P., Gulik, A., Bourdon, O., Gref, R., Labarre, D., Barratt, G., 2001a. Relationship between complement activation, cellular uptake and physicochemical aspects of novel PEG-modified nanocapsules. Biomaterials 22, 2967-2979.

Mosqueira, V.C.F., Legrand, P., Morgat, J., Vert, M., Mysiakine, E., Gref, R. Devissaguet, J.-P., Barratt, G., 2001b. Biodistribution of long-circulating PEG-grafted nanocapsules in mice: effects of PEG chain length and density. Pharm. Res. 18, 1411-1419.

Neves, B.R.A., Vilela, J.M.C., Andrade, M.S., 1998. Microscopia de varredura por sonda mecânica: uma introdução. Cerâmica 44, 212-219.

Otsubo, T., Maesaki, S., Hossain, M.A., Yamamoto, Y., Tomono, K., Tashiro, T., Seki, J., Tomii, Y., Sonoke, S., Kohno, S., 1999. In vitro and in vivo activities of NS-718, a new lipid nanosphere incorporating amphotericin B, against Aspergillus fumigatus. Antimicrob. Agents Chemother. 43, 471475 .

Owens III, D.E., Peppas, N.A., 2006. Opsonization, biodistribution, and pharmacokinetics of polymeric nanoparticles. Int. J. Pharm. 307, 93-102.

Pascual, A., Garcia, I., Conejo, C., Perea, E.J., 1993. Uptake and intracellular activity of fluconazole in human polymorphonuclear leukocytes. Antimicrob. Agents Chemother. 37, 187-190.

Prakobvaitayakit, M., Nimmannit, U., 2003. Optimization of polylactic-coglycolic acid nanoparticles containing itraconazole using $2^{3}$ factorial design. AAPS Pharm. Sci. Technol. 4, 1-9.

Schaffazick, S.R., Guterres, S.S., Freitas, L.L., Pohlmann, A.R., 2003. Caracterização e estabilidade físico-química de sistemas poliméricos nanoparticulados para administração de fármacos. Química Nova 26, 726-737.

Torchilin, V.P., 2000. Drug targeting. Eur. J. Pharm. Sci. 11, 81-91. 